\title{
$\mathrm{u}$-Learning 시대의 교사양성 체제 모형 연구
}

\author{
박정환 ${ }^{1}$, 정동욱 $^{2 *}$, 박형성 ${ }^{3}$ \\ ${ }^{1}$ 제주대학교 교육학과, ${ }^{2}$ 버지니아대학교, ${ }^{3}$ 영화초등학교
}

\section{A Study on a Model of Teacher Education System in u-Learning}

\author{
Jung-Hwan Park ${ }^{1}$, Dong-Uk Cheong ${ }^{2^{*}}$ and Hyung-Sung Park ${ }^{3}$ \\ ${ }^{1}$ Dept of Education, Jeju National University, ${ }^{2}$ University of Virginia, \\ ${ }^{3}$ Young Hwa Elementary School
}

\begin{abstract}
요 약 이 연구의 목적은 u-Learning 시대에 교육의 변화를 주도할 수 있는 교원양성체제의 모형을 제시하는데 있 다. 이 목적을 달성하기 위하여 첫째, 현재의 교원양성체제를 고찰하였다. 둘째, 교원양성체제에 활용될 수 있는 유비 쿼터스 기술을 분석하였다. 셋째, 기술 분석을 토대로 교원양성체제 구성요소 간 커뮤니케이션을 지원하는 유비쿼터 스 기능을 탐색하였다. 마지막으로 u-Learning 시대의 교원양성 체제에 대한 예비교사들의 인식, 필요성, 요구사항 등 을 분석하였다. 이러한 연구를 토대로 u-Learning 시대에 적합한 교원양성체제의 모형을 제시하였다. 이 연구에서 제 시하는 교원양성체제 모형은 u-Learning 시대를 주도할 교사 양성에 도움을 줄 수 있을 것이다.
\end{abstract}

\begin{abstract}
The purpose of this research is to develop a model of teacher education system in u-Learning age. To achieve the purpose, first, the current teacher education system was analyzed. Second, ubiquitous technologies which could be used in future teacher education system were analyzed. Third, functions of ubiquitous technologies supporting communication between the elements of teacher education system were explored based on the analysis of the technologies. Forth, researchers analyzed pre-service teachers' understanding, needs, and demands for the future teacher education system in u-Learning age. The model of teacher education system which is appropriate for u-Learning age was proposed based on the results of analyses. The developed model could help to educate pre-service teachers who will lead the education in u-Learning age.
\end{abstract}

Key Words : Pre-service teacher education, Model of teacher education system, u-Learning

\section{1. 서론}

지식기반사회에서 국가 경쟁력을 좌우하는 우수한 교 사 없이는 우수한 인재를 길러낼 수 없다는 평범한 논리 에 근거하여 보면, 지식기반사회에 적합한 인재를 양성할 만한 자질과 전문성을 지닌 우수한 교사를 양성하는 일 은 무엇보다 중요한 일이다[1]. 이에 비하여 그 동안 우리 의 교원양성정책은 종합적인 방향 수립과 전문성 향상을 위한 체계적이고 집중적인 노력보다는 양적 수급에만 급 급한 채 양성기관이 설립되고 정원이 책정되어 사회의 변화에 빠른 대처가 부족하다는 지적이 제기되어 왔다.
우리나라의 교원양성체제의 문제점에 대한 학자들의 의견을 정리하면[2-6], 첫째, 교원수급의 불균형으로 인한 교원 질 관리가 제대로 되고 있지 않음, 둘째, 교원양성 교육기관의 정체성 부족, 셋째, 특색 없는 교원양성교육 과정이 편성·운영되고 있어 교원양성기관의 특성화가 부족하며 교원의 전문성 육성에 기여도가 낮음, 넷째, 교 원양성 교육기관과 중등학교 현장과의 연계성이 요구됨, 다섯째, 교원양성기관의 교육여건이 미흡함, 여섯째, 교 육과정에 교육현장의 요구반영이 미흡함, 일곱째, 중등학 교 교육과정 개정이 교원양성 교육기관의 교육과정과 연 계되지 못하고 있는 점 등이다.

이 논문은 2006년도 정부재원(교육과학기술부 학술연구조성사업비)으로 한국학술진흥재단의 지원을 받아 연구되었음 (KRF-2006-321-B00724).

*교신저자 : 정동욱(duc8n@virginia.edu)

접수일 09년 09월 20일 수정일 09년 10월 26일 
최근 정보통신기술의 발달로 인하여 다양한 종류의 컴 퓨터가 네트워크로 연결된 유비쿼터스 환경이 인간생활 에 영향을 미치고 있다. 박정환[12]의 연구에서도 언급했 듯이 유비쿼터스 환경은 초중등 교육에도 많은 변화를 가져올 것으로 예상되며, 미래 교원을 양성하는 교원양성 기관에서는 이 변화에 대응할 수 있는 교원양성에 대비 해야 한다.

나아가 유비쿼터스 환경은 앞서 제시한 교원양성체제 의 문제점을 완화 또는 해결할 가능성을 가지고 있다. 학 교현장과 양성기관을 연결하는 유비쿼터스 컴퓨팅 환경 은 양성기관의 이론중심의 교육과정을 실제와 연결시키 는 역할을 할 수 있으며 양성기관과 학교 현장과의 연계 성을 강화할 가능성을 가지고 있다. 그리고 예비교사의 학습과 양성기관 교수자의 교수 및 협력학교를 지원하는 유비쿼터스 커뮤니케이션은 교원양성기관의 교육여건을 개선하고 특색 있는 교육과정 운영에 기여할 것이다. 따 라서 이 연구에서는 u-Learning 시대에 교육의 변화를 주 도할 교사를 양성할 수 있는 교원양성체제의 모형을 제 시하고자 한다.

\section{2. 연구 방법}

이 연구는 u-Learning 시대 교원양성 체제 모형 개발 을 위해 분석단계, 조사단계, 설계 및 개발단계를 거쳐 수 행되었다. 분석단계에서는 첫째, 현재의 교원양성체제를 고찰하고, 유비쿼터스 시대에 적합한 교원양성체제의 과 제와 그 수행 방안을 탐구하였으며, 둘째, 교원양성체제 에서 활용될 수 있는 유비쿼터스 기술을 분석하였고, 셋 째, 교원양성체제의 구성요소 간 커뮤니케이션을 지원하 는 유비쿼터스 기능들을 탐색하였다. 조사단계에서는 분 석단계에서의 분석 결과를 기반으로 u-Learning에 대한 예비교사의 인식, 필요성, 요구사항 등을 고찰하였다. 설 계 및 개발단계에서는 분석 및 조사단계의 연구 결과를 기반으로 u-Learning 시대의 교원양성체제를 설계하고 개발하였다.

\section{3. 모형개발을 위한 관련 연구}

\section{1 교원양성 체제 분석}

\subsection{1 교사양성 체제의 현황 및 문제점 분석}

현재 중등학교 교사는 사범대학, 일반대학의 교육과, 일반대학의 교직과정, 그리고 교육대학원 등 다원화된 양
성기관을 통해 양성되고 있다. 2009년 현재 중등교원 양 성기관의 현황을 보면 사범대학을 설치하고 있는 대학은 국립 14 개교, 사립 28 개교로서 총 42 개교이며, 일반대학 에 $\bigcirc \bigcirc$ 교육과를 설치하고 있는 대학은 국립 6 개교, 사립 53 개교로서 총 59 개교, 일반대학에 교직과정을 설치하고 있는 대학은 국 - 공립 33 개교, 사립 125 개교로서 총 158 개교, 그리고 교육대학원을 설치하고 있는 대학은 국·공 립 35개교, 사립 99개교로서 총 134개교이다[7].

우리나라의 중등교원양성체제는 사범학교나 사범대학 을 두어 교원을 양성하는 목적형 체제와 교직과정 이수 나 학부를 졸업한 학생들이 교육대학원을 졸업한 후 교 사가 되는 개방형 체제가 동시에 존재한다. 사범대학은 그동안 중등교원을 양성하는데 중추적 역할을 해왔으나, 일반대학 교직과정, 교육대학원 등에서도 양성하는 개방 형체제를 유지하다보니 과잉 공급으로 인하여 사범대학 의 정체성 문제와 교육과정 운영 부실의 문제를 야기 시 켰다[8]. 또한 사범대학 교육과정, 일반대학 교직과정의 교육과정, 교육대학원의 교육과정 별 특색 있는 차이를 찾아보기 힘들다는 지적이 있다. 일반 대학과 차별성이 없는 교육과정 편성운영은 결국 교원의 전문성과 질의 문제로 귀결된다. 사범대학의 정체성 문제는 교육과정의 전문성과 관련된다. 사범대학이 교원양성에 부합하는 교 육과정으로 운영하기보다는 학문 위주의 일반대학 교육 과정과 거의 비슷하게 운영하다보니 학교 현장에서 필요 로 하는 교사를 제대로 양성하지 못한다는 문제가 제기 되고 있다. 또한 사범대학 교육과정 운영 부실의 문제는 교원자격의 질 관리 장치의 결여와 관련된다. 이는 졸업 성적에 관계없이 과정 이수자 모두에게 자격증을 수여하 는 것이 그 원인이다. 이에 반하여 교직과정 이수자는 이 수학점과 성적에 대한 제한이 있다. 그 외에도 교사자격 증 과잉 배출에 따른 교원 임용율 저하로 우수한 인재들 이 교직진출을 기피하는 등 여러 가지 문제가 있다.

\subsection{2 교원양성 체제 분석의 시사점}

교원양성 체제 분석은 교원양성기관의 특성화, 학교현 장의 변화 및 요구가 반영된 교육과정 편성, 그리고 교육 실습과정 보강의 측면에서 u-Learning 시대 교원양성체 제 모형에 시사하는 바가 있다.

교원양성기관의 특성화 측면에서 첫째, 사범대학 및 사범계 학과는 장기적으로 국민공통기본교과를 담당하는 교사 양성에 중점을 두도록 해야 한다. 둘째, 일반대학 교 직과정은 장기적으로 사범대 및 사범계 학과에서 양성하 지 않는 분야로 특성화해야 한다. 셋째, 교육대학원은 양 성기능을 장기적으로 없애고 그 본래의 연수기능을 확대 해야 한다. 
학교현장의 변화 및 요구가 반영된 교육과정 편성 측 면에서 첫째, 현재 2009학년도 사범대 입학생부터 적용 될 예정인 학생문화, 학급관리와 학생지도, 부진아 및 영 재 아동의 지도, 교수법, 사회변화와 교직윤리 등의 교직 과목 보강은 계속 유지 및 확대되어야 한다. 둘째, 실제 학생 교육을 담당하고 있는 교원들의 요구 및 제안이 교 원교육기관에 전달될 수 있는 의사소통 채널을 구축하여 교원양성기관이 현장의 요구와 사회의 요구에 신속하게 적응할 필요가 있다. 셋째, 학교 현장의 교육과정이 개편 되면 교원양성기관의 교육과정도 일정부분 개편될 필요 가 있다. 넷째, 학교현장의 실제 상황 장면의 일부를 교원 양성기관과 공유할 필요가 있다. 부설학교의 수업과정 및 교사의 학생 지도 장면이 실시간 또는 비 실시간으로 교 원양성기관에 제공된다면, 이러한 실제적 상황이 예비교 사교육에 좋은 사례로 활용될 수 있을 것이다. 마지막으 로, 학교현장의 직무수행용 전산망이 교원양성기관에 실 습용으로 제공되어 예비교사들이 이를 체험할 기회를 제 공하는 것이 필요하다.

교육실습 과정 보강의 측면에서는 우선, 교원양성기관 과 실습학교 간 연계 활성화가 전제된 교육실습 운영이 필요하다. 이를 위해 각 교원양성기관 별 부설학교 확대 나 고정적인 실습학교의 확보가 필요하다. 둘째, 교원양 성기관은 부설학교나 실습학교 지원방안을 마련해야 한 다. 교원양성기관은 예비교사의 교육실습이 실습학교와 실습담당교사 그리고 그 학생들에게 어떤 기여를 할 수 있을지에 대한 고민을 해야 할 것이다. 셋째, 교육실습 프 로그램의 일반적 기준의 개발이 필요하며, 교원양성기관 은 실습학교 및 담당교사가 교육실습생의 실습을 잘 안 내할 수 있도록 현실적이고 구체적인 실습 프로그램을 제시해야 한다.

\section{2 유비쿼터스 기술 분석}

\subsection{1 유비쿼터스 기술 분석 결과}

최근 IT 기술의 발달로 인해 다양한 종류의 컴퓨터가 사람, 사물, 환경 속으로 스며들고, 이들이 네트워크로 연 결되어 인간의 삶을 도와주는 유비쿼터스 환경이 급속히 진전되고 있으며[9], 유비쿼터스 환경은 교육, 정치, 의료, 가전, 통신 등 전 분야에서 응용되어 사회 변화와 인간 생활의 변화를 주도 하고 있다. 유비쿼터스 컴퓨팅 환경 은 모든 컴퓨터가 네트워크 상에 존재하는 상태에서 상 호연결에 의해 의미가 더해진다. 유비쿼터스 기술은 각 객체들이 네트워크 상에서 서로 연결되어 서로 정보를 요구하거나 특정 기능을 수행하도록 요구하는 기술로 유 비쿼터스 컴퓨팅의 중요한 환경적 요소이다.
유비쿼터스 기술은 현재의 교육에도 많은 변화를 일으 키고 있다. 사람이 컴퓨터 앞에 앉지 않고서도 언제 어디 서든지 인터넷에 접속해 모든 생활환경을 원격으로 조정 할 수 있는 유비쿼터스 환경은 교육환경에도 많은 변화 를 가져왔다. 이 환경은 강의실이라는 시공간적으로 폐쇄 된 울타리를 벗어나 언제(anytime), 어디서나(anywhere), 누구(anyone)에게나 자신이 필요로 하는 교육 서비스를 받을 수 있는 교육환경을 만들어 내고 있다[10].

$\mathrm{u}$-Learning 환경 구축을 위한 노력은 대학의 u-Campus 구축 사례[11]를 통해 확인해볼 수 있다. 각 대학들은 종 합정보시스템, 전자도서관, 스마트카드시스템 등을 구축 하여 u-Campus 기반을 조성해나가고 있다. 이러한 $\mathrm{u}$-Learning 환경이 기존의 e-Learning과 $\mathrm{m}$-Learning 환경 과 다른 점은, $\mathrm{u}-$ Learning 환경이 이들의 기능을 모두 포 함하면서 사이버공간을 물리적 공간에 내제시켜 사용자 가 컴퓨터를 인식하지 않으면서 일상생활에서 이를 활용 하도록 하는 것이다[11].

\subsection{2 유비쿼터스 기술 분석의 시사점}

예비교사 교육을 위한 유비쿼터스 컴퓨팅 환경 구축의 궁극적인 목표는 이론과 실제의 간격을 좁히고 그 연결 을 매끄럽게 하는 것이며, 이를 통해 예비교사들의 교수 기술과 방법, 학급관리 기술 등 이론적 지식을 실천할 수 있는 능력의 향상을 꾀하는 것이다. 다음에 제시되는 사 례는 u-Learning 환경에서 유비쿼터스 기술이 사범대학 의 예비교사 교육에 활용되는 모습을 상상할 수 있는 가 상의 사례이다.

\section{<사례1>}

“학급경영”과목의 A교수는 해당 주제에 대한 이론적 인 강의 후에 실제 현장 교실의 다양한 사례를 학생들에 게 제시하면서 이론과 실제가 결부된 생생한 교직과목 수업을 하였다. 또한 사전에 협의된 교사의 수업을 실시 간 영상 전송장비 및 화상 시스템을 통해 학생들에게 보 여주었다.

\section{<사례2>}

사범대학에 다니는 $\mathrm{B}$ 예비교사는 사범대학에 개설된 교직과목 중 “학급경영”에 대한 수업을 듣고 구체적인 사례와 교사의 경영 기술을 알고 싶었다. 수업이 끝난 후 이 예비교사는 유비쿼터스 환경의 캠퍼스에서 복도의 라 운드 테이블 공간에서 학생에게 내장된 자동인식기술을 통해서 원하는 정보 제공을 요구하였다. 유비쿼터스 기술 이 내장된 복도 공간은 3 차원 인터뷰 장소 및 현장 교실 의 다양한 사례를 확인하는 가상공간으로 변하게 된다. 
이 예비교사는 현장 교사 중 학급경영 기술이 뛰어난 전 문가를 선택하여 20 분 인터뷰를 통해 현장의 구체적인 정보를 얻고, 또한 학급경영과 관련된 다양한 구체 사례 를 체험하였다.

\section{<사례3>}

사범대학에 다니는 $\mathrm{C}$ 예비교사는 현장의 교무업무지원 시스템을 알고 싶었다. 현장 학교의 교무업무시스템 담당 자는 $\mathrm{C}$ 예비교사가 접근할 수 있는 제한된 정보를 사용할 수 있는 계정을 열어주었다. 현장 학교의 $\mathrm{D}$ 교사는 사범 대학 도서관 웹사이트에서 필요한 논문과 도서검색이 필 요하였다. 이 사범대학에서는 협력학교 교사에게 도서관 을 이용할 수 있는 자격 및 계정을 주었다. 이 두 사람은 두 기관의 협력적 커뮤니케이션 시스템을 활용하여 자신 에게 필요한 정보를 얻을 수 있었다.

이 가상의 사례는 미래형 교원양성체제의 일면에 대한 상상을 도울 수 있으며, 교수자와 학습자 그리고 관련 기 관 간 효율적인 커뮤니케이션 지원의 가능성을 보여준다.

\section{3 커뮤니케이션을 지원하는 유비쿼터스 기능}

교원양성체제의 개선과 보완을 위하여 현재까지 개발 된 유비쿼터스 기술의 이점을 활용하기 위해서는 그 기 술이 교원양성체제를 구성하고 있는 요소간의 커뮤니케 이션을 지원하도록 하는 것이다. 유비쿼터스 기술이 미래 형 교원양성체제에서 지원하는 커뮤니케이션 기능은 교 수지원기능, 학습지원기능, 그리고 양성기관과 학교현장 간 지원기능으로 구분하여 볼 수 있다.

\subsection{1 교수지원 커뮤니케이션}

교수지원 커뮤니케이션은 크게 대학 교수자와 예비교 사 간 커뮤니케이션, 교수자와 교수 자료 간 커뮤니케이 션, 교수자와 부설학교와의 커뮤니케이션으로 구분하여 볼 수 있다. 아래의 표 2는 u-Campus에서 가능한 교수지 원 기능을 가진 커뮤니케이션을 정리한 것이다.

[표 1] 교수지원 커뮤니케이션

\begin{tabular}{|c|c|c|}
\hline 대상 & 내용 & 사용기기 \\
\hline $\begin{array}{l}\text { 교수자와 } \\
\text { 예비교사 }\end{array}$ & \begin{tabular}{|l|} 
강의자료 실시간 접근 \\
학생 출결, 과제물 관리 시스템 \\
강의관련 공지사항 SMS 서비스 \\
학생 상담 및 일정관리 프로그램 \\
B-Learning(옥오프라인 강의 연계) \\
학생 질문 예약 서비스 \\
지능형 전자칠판 활용 강의노트 제공 \\
모바일 기기를 이용한 실시간 평가
\end{tabular} & \begin{tabular}{|c|} 
전자 학생증 \\
휴대폰 \\
컴퓨터
\end{tabular} \\
\hline
\end{tabular}

\begin{tabular}{|c|c|c|}
\hline $\begin{array}{l}\text { 교수자와 } \\
\text { 교수자료 }\end{array}$ & $\begin{array}{l}\text { 강의의 자동적 e-Learning 콘텐츠화 } \\
\text { 강의의 온라인 중계 서비스 } \\
\text { 지능형 전자칠판 강의자료 활용 } \\
\text { 국·내외 학술자료 검색 및 열람 } \\
\text { 부설학교 현장의 자료 활용 } \\
\text { 지능형 전자 신분증 활용 }\end{array}$ & $\begin{array}{c}\text { 전자 신분증 } \\
\text { 컴퓨터 } \\
\text { PDA }\end{array}$ \\
\hline $\begin{array}{l}\text { 교수자와 } \\
\text { 부설학교 }\end{array}$ & $\begin{array}{l}\text { 부설학교와 화상시스템 활용 } \\
\text { - 수업 및 교수자간 교류 }\end{array}$ & $\begin{array}{l}\text { 화상시스템 } \\
\text { 컴퓨터 }\end{array}$ \\
\hline
\end{tabular}

\subsection{2 학습지원 커뮤니케이션}

예비교사를 위한 u-Campus 학습지원 커뮤니케이션은 크게 예비교사와 대학 교수자 간 커뮤니케이션, 예비교사 와 학습자료 간 커뮤니케이션, 예비교사와 실습학교 간 커뮤니케이션으로 구분할 수 있다. 아래의 표 3 은 u-Campus에서 학습지원 기능을 가진 커뮤니케이션을 정 리한 것이다.

[표 2] 학습지원 커뮤니케이션

\begin{tabular}{|c|c|c|}
\hline 대상 & 내용 & 사용기기 \\
\hline $\begin{array}{l}\text { 예비교사 } \\
\text { 와 } \\
\text { 교수자 }\end{array}$ & $\begin{array}{l}\text { 강의자료 실시간 접근 } \\
\text { 학생 출결, 과제물 관리 시스템 } \\
\text { 강의관련 공지사항 SMS 서비스 } \\
\text { 학생 상담 및 일정관리 프로그램 } \\
\text { B-Learning(온오프라인 강의 연계) } \\
\text { 학생 질문 예약 서비스 } \\
\text { 지능형 전자칠판 활용 강의노트 제공 } \\
\text { 모바일 기기를 이용한 실시간 평가 }\end{array}$ & $\begin{array}{c}\text { 전자 } \\
\text { 학생증 } \\
\text { 휴대폰 } \\
\text { PDA } \\
\text { 컴퓨터 }\end{array}$ \\
\hline $\begin{array}{l}\text { 예비교사 } \\
\text { 와 } \\
\text { 학습자료 }\end{array}$ & $\begin{array}{l}\text { e-Learning 강의 콘텐츠 이용 } \\
\text { 지능형 전자칠판 강의자료 활용 } \\
\text { 국·내외 학술자료 검색 및 열람 } \\
\text { 학교 현장의 자료 활용 } \\
\text { 지능형 전자 신분증 활용 }\end{array}$ & $\begin{array}{l}\text { 컴퓨터 } \\
\text { PDA }\end{array}$ \\
\hline $\begin{array}{l}\text { 예비교사 } \\
\text { 와 } \\
\text { 부설학교 }\end{array}$ & $\begin{array}{l}\text { 부설학교와 화상시스템 활용 } \\
\text { - 교사와 예비교사 교류 } \\
\text { 부설학교의 교무업무시스템 활용 }\end{array}$ & $\begin{array}{c}\text { 화상시스템 } \\
\text { 컴퓨터 }\end{array}$ \\
\hline
\end{tabular}

\subsection{3 양성기관과 학교현장 간 지원 커뮤니케이션}

교원양성기관은 교사를 양성하는 것이 기본 목표이다. 표 4는 양성기관과 부설학교 간 커뮤니케이션 서비스와 양성기관 교원과 부설학교 교원 간 커뮤니케이션 지원 시비스로 정리한 것이다. 이러한 서비스는 교원양성기관 과 부설학교의 유기적 관계를 맺고 교원양성 및 교육발 전에 좋은 계기를 만드는데 도움이 될 것이다. 
[표 3] 양성기관과 학교현장 간 커뮤니케이션

\begin{tabular}{|c|c|c|}
\hline 대상 & 내용 & 사용기기 \\
\hline $\begin{array}{l}\text { 양성기관 } \\
\text { 과 } \\
\text { 부설학교 }\end{array}$ & $\begin{array}{l}\text { 부설학교 교원이 양성기관 이용 자격 부여 } \\
\text { 교무업무시스템의 일부를 양성기관에 제공 } \\
\text { 부설학교의 교수-학습 장면을 제공 } \\
\text { 양성기관와 부설학교 교원 간 화상시스템 }\end{array}$ & $\begin{array}{l}\text { 전자인증서 } \\
\text { 교무업무시 } \\
\text { 스템 } \\
\text { 컴퓨터 }\end{array}$ \\
\hline $\begin{array}{l}\text { 양성기관 } \\
\text { 교원과 } \\
\text { 부설학교 } \\
\text { 교원 }\end{array}$ & $\begin{array}{l}\text { 부설학교의 수업 장면을 양성기관에 제공 } \\
\text { 교육실습을 위한 화상시스템 제공 } \\
\text { 예비교사 공개수업을 중계하고 피드백 교환 }\end{array}$ & $\begin{array}{c}\text { 화상시스템 } \\
\text { 컴퓨터 }\end{array}$ \\
\hline
\end{tabular}

\section{4 u-Learning에 대한 예비교사의 인식 분석}

\subsection{1 u-Learning에 대한 예비교사 인식}

u-Learning 시대의 교원양성 체제 모형을 구안하기 위 하여 박정환[1]의 연구에 근거하여 예비교사의 지식을 보 는 관점, 현장과 연계한 교육활동, 정보통신기술(ICT)에 대한 인식을 정리하면 다음과 같다.

첫째, 교사는 지식과 정보의 생산자이면서 평생학습자 이다. 예비교사들은 교사가 지식과 정보의 생산자이라는 의견에 $49 \%$ 가 긍정을 하였으며, 평생학습자라는 의견에 $83 \%$ 가 긍정을 하였다. 이는 예비교사 교육기관에서 지식 이 맥락성을 지니고 실제와 밀접한 관련이 있는 주제로 다루어져야 하며, 이론을 통한 지식의 습득뿐만 아니라 실제 문제와 상황에 기반한 경험을 통한 학습이 필요함 을 시사한다.

둘째, 사범대학의 교육과정은 현장과 연계되어야 한 다. 예비교사들은 현행 교사교육이 현장에 대한 지식과 실무능력을 익히기에 충분한가에 대한 질문에 $59 \%$ 가 부 정하였으며, 앞으로 사범대학 수업에서 필요한 현장 연계 교육방법에 대해 $45 \%$ 가 현직교사의 수업 또는 특강을, $31 \%$ 가 유비쿼터스 매체 활용을 선택하였다. 이는 양성기 관에서의 교육이 학교 현장과의 연계를 통해 예비교사들 에게 다양한 현장의 정보를 제공할 수 있도록 보완되고 개선될 필요가 있음을 시사하고 있다. 특히 이를 개선하 기 위하여 현장 교사의 수업을 활용해야 하며, 유비쿼터 스 기술을 기반으로 현장교사의 수업을 활용할 수 있는 시스템을 운영해야 함을 시사한다.

셋째, 미래의 교원양성 프로그램의 일환으로 u-Learning 환경이 구축되어야 한다. 예비교사들은 현장 과 연계된 교원양성 프로그램의 일환으로 u-Learning 환 경 구축의 필요성에 대하여 $70 \%$ 가 긍정하였다. 이는 유 비쿼터스 환경이 다양한 첨단 기술을 통해 일선학교와 대학 간의 의사소통의 폭을 확대할 필요가 있음을 시사 하고 있다.

넷째, u-Learning 환경에서는 상호작용 증진을 위해 디
지털 커뮤니케이션 기술이 활용되어야 한다. 예비교사들 은 정보통신기술이 상호작용 증진에 관련이 있다는 의견 에 $79 \%$ 가 긍정하였다. 이는 교수자와 학습자의 상호작용 과 피드백 활성화를 위해 다양한 형태의 정보통신기술이 활용되어야 함을 시사하고 있다.

\subsection{2 예비교사 인식 분석의 시사점}

예비교사 양성과정에서 실제 문제와 상황에 기반한 경 험을 제공할 필요가 있으며, 이를 위해 학교현장의 다양 한 정보, 특히 현장 교사의 수업 장면을 양성과정에서 활 용할 수 있도록 해야 한다. 또한 예비교사들의 실무능력 향상을 위해 정보통신기술을 활용한 일선학교와 대학 간 협력 시스템 구축이 필요하다. 양성기관 내에서도 교수자 와 학습자의 상호작용 증진을 위한 디지털 커뮤니케이션 기술이 활용되어야 한다. 교원양성을 위한 u-Learning 환 경 구축은 이러한 필요성과 요구들을 일정부분 충족시킬 수 있을 것이다.

\section{4. u-Learning 시대의 교원양성체제 모형 개발}

이 연구는 u-Learning 시대의 교원양성체제 모형을 개 발하는 것이다. 이를 위해 분석단계에서 현행 교원양성 체제를 분석하였고, 유비쿼터스 기술을 분석하였으며, 교 원양성체제의 구성요소 간 유비쿼터스 커뮤니케이션 지 원 기능을 탐색하였다. 조사단계에서는 u-Learning에 대 한 예비교사의 인식을 고찰하였다. 설계 및 개발단계에서 는 분석 및 조사단계의 연구 결과를 기반으로 '교원양성 기관의 특성화,' '교원양성체제의 구성요소 간 상호작용 지원,' ‘양성기관과 학교 현장 간의 교류 지원'을 u-Learning 시대의 교원양성체제의 목표로 설정하였다. 설정된 목표에 따라 교원양성체제의 구체적인 하위 기능 들을 제시하였다. 이를 세 가지 목표를 기준으로 정리하 면 다음과 같다.

u-Learning 시대의 교원양성이 성공적이기 위해서는 첫째, 교원양성기관이 특성화 되어야 한다. 사범대학 및 사범계 학과는 장기적으로 국민공통기본교과를 담당하는 교원양성에 중점을, 일반대학 교직과정은 사범대 및 사범 계 학과에서 양성하지 않는 교과를 담당하는 교원 양성 에 중점을 두어야 하며, 교육대학원은 양성기능을 장기적 으로 없애고 그 본래의 연수기능을 확대해야 한다. 


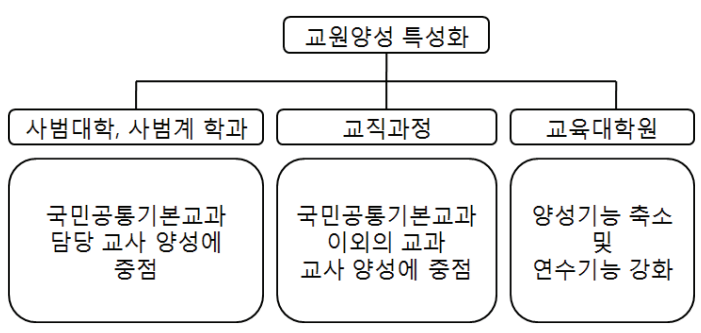

[그림 1] 교원양성기관 특성화

둘째, 교원양성체제의 구성요소 간 상호작용을 지원해 야 한다. 이를 위해 첫째로는, 양성기관의 유비쿼터스 환 경은 교수자의 교수를 효과적으로 지원해야 한다. 즉, 이 환경은 양성기관의 교수자가 예비교사, 교수 자료, 그리 고 부설학교와 효과적인 커뮤니케이션을 할 수 있도록 지원해야 한다. 유비쿼터스 환경은 교수자로 하여금 예비 교사들의 출결과 과제물 및 평가 관리, 공지사항 전달, 예비교사의 질의에 대한 응답 등을 효율적으로 행할 수 있도록 지원해야 한다. 또한 교수자 강의의 e-Learning 콘 텐츠화, 강의의 온라인 중계, 지능형 전자칠판 강의 자료 의 활용, 부설학교의 자료 활용, 국내외 학술자료 활용 등 을 지원해야 한다. 나아가 교수자가 영상전송 시스템을 활용하여 부설학교의 현장 수업을 양성기관 강의에 활용 할 수 있도록 지원해야 한다. 둘째로는, 양성기관의 유비 쿼터스 환경이 예비교사의 학습을 효과적으로 지원해야 한다. 즉, 이 환경은 예비교사가 교수자, 학습 자료, 그리 고 부설학교의 자료와 효과적인 커뮤니케이션이 이루어 지도록 지원해야 한다. 유비쿼터스 환경은 예비교사의 출 결, 과제물 관리, 교수자와의 상담 및 질의/응답, 평가, 공 지사항 수신, 수강 일정관리 등을 지원해야 한다. 또한 예 비교사로 하여금 교수자 강의 자료의 실시간 접근, 지능 형 전자칠판에서 사용한 교수자의 강의노트 활용, e-Learning 강의 콘텐츠 활용, 부설학교의 자료 활용 등을 효율적으로 할 수 있도록 지원해야 한다. 나아가 예비교 사가 영상전송 시스템을 활용하여 부설학교의 현장 수업 을 실시간으로 활용할 수 있도록 지원해야 하며, 부설학 교의 교무업무시스템을 활용할 수 있도록 지원해야 한다.

셋째, 양성기관과 학교 현장과의 교류를 지원해야 한 다. 즉, 양성기관의 유비쿼터스 환경은 양성기관 소속 교 원 및 학생으로 하여금 부설학교의 교수-학습 장면을 활 용할 수 있도록 해야 하며, 예비교사들의 실습을 위해 교 무업무시스템의 일부를 사용할 수 있도록 해야 한다. 또 한 부설학교의 교원이 양성기관의 여러 시설 및 교육에 관련된 정보를 사용할 수 있도록 지원해야 한다.

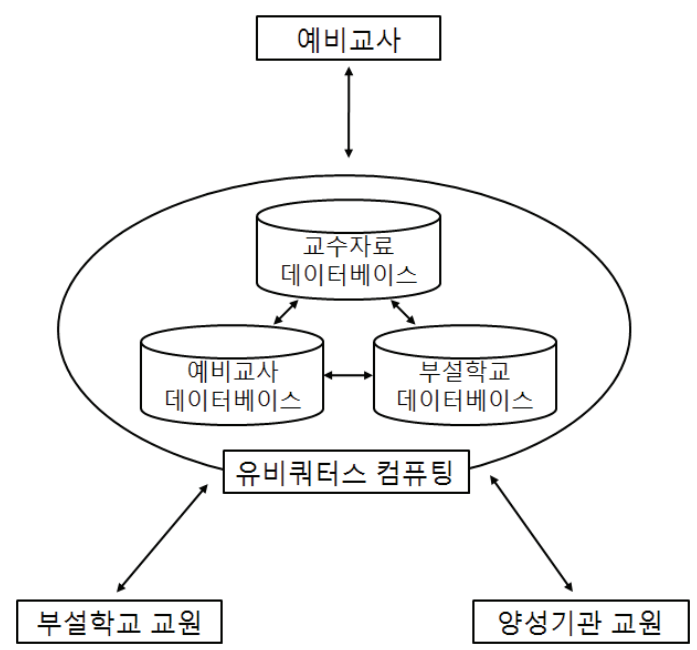

[그림 2] 교원양성체제 구성요소 간 상호작용

\section{5. 결론}

본 연구에서는 u-Learning 시대에 교육의 변화를 주도 할 수 있는 교원양성 체제의 모형을 제시하고자, 현재의 교원양성 체제를 분석하고 유비쿼터스 시대에 변화해야 하는 교원양성 체제의 문제점을 찾고 그 해결책을 연구 하였다. 그리고 교원양성 체제에서 활용될 수 있는 유비 쿼터스 기술을 분석하여 교원양성체제의 구성요소 간 효 과적인 커뮤니케이션을 지원하는 유비쿼터스 기능을 제 시하였다. 이러한 연구 결과를 기반으로 u-Learning 시대 의 교원양성체제 모형을 제시하였다. 이 모형이 양성기관 에 적용되기 위해 필요한 조건들에 대한 논의는 다음과 같다.

교원양성기관의 특성화 측면에서, 사범대학 및 사범계 학과, 일반대학 교직과정, 교육대학원이 각각 고유의 역 할을 수행하기 위해서는 제도적, 행정적으로 해결해야 할 행정부의 역할과 각 대학 간 교육과정 및 체제 개편을 위 한 양성기관의 역할이 구분되어 수행되어야 할 것이다.

교원양성체제 구성요소 간 상호작용 지원의 측면에서, 유비쿼터스 환경은 예비교사의 자기주도적 학습이 가능 하도록 설계되고, 인간중심의 서비스가 제공되어야 한다. 또한 교수자와 학습자의 상호작용과 피드백 활성화가 중 요하며, 이를 위해서는 다양한 형태의 정보통신기술이 접 목되어 상호작용을 증진시켜야 한다. 나아가 정보통신 기 술의 발전과 현장적용을 통해서 나타나는 정보통신 윤리 의 문제에서는 예비교사, 또는 교사의 정보윤리에 대한 가치관 정립이 필요하다. 
양성기관과 학교 현장과의 교류 지원의 측면에서, 다 양한 형태의 유비쿼터스 기술을 활용한 교육현장과 양성 기관의 교류가 있어야 한다. 또한 유비쿼터스 기술을 기 반으로 현장교사의 수업을 관찰하고 질의응답이 가능한 시스템을 운영, 현장교사와 직접 상호작용이 이루어지는 실질적인 교육실습이 요구된다.

유비쿼터스 환경의 도래는 학교현장의 교육방법에 새 로운 변화를 가져올 것이다. 유비쿼터스 환경에서 양성교 육을 받은 예비교사들은 학교현장의 유비쿼터스 환경 변 화에 대처할 수 있는 역량을 잠재적으로 가지게 될 것이 다. 따라서 향후 유러닝을 위한 예비교사 역량에 대한 보 다 깊이 있는 연구가 요구된다.

\section{참고문헌}

[1] 박정환, u-Learning 시대의 교사양성 체제 연구, 2006 년도 학진 기초연구과제(KRF-2008-003-B00303) 보고 서, 2008.

[2] Hook,S, Education for Modern Man, New York : Alfred A. Knopt. 1967.

[3] 전남대학교 교육발전연구원, 대학의 최신 교수-학습 방법, 학지사, 2006.

[4] 손충기, 교사의 교수행동 진단 척도 개발과 그 타당 화 연구, 인하대학교 대학원 박사학위논문, 1994.

[5] 주삼환, 장학론, 문음사, 1996.

[6] 강영삼, 이윤식, 조병효, 주상환, 진동섭, 장학론, 하 우출판사, 1995.

[7] 교육과학기술부, 2009년 교원양성기관 현황, 교육과 학기술부 웹사이트(http://www .mest.go.kr), 2009.

[8] 황영준, 교원전문대학원 도입의 쟁점 및 발전적 대안 탐색, 한국교원교육학회, 제22권 제2호, pp. 139-157, 2005.

[9] 류영달, U-Korea 추진의 필요성과 전략, $\mathrm{NCA} \mathrm{CIO}$ REPORT 04-04호, 한국전산원, 2004.

[10] 차명호, 정선호, 유비쿼터스 러닝 시스템의 필요성 에 대한 연구, 평택대학교 논문집, 18, pp. 365-381, 2004.

[11] 한국교육학술정보원, 대학정보화 최신 동향 분석 자 료집: 건국대, u-Campus 구축사례, RM 2006-63, pp. 164-171, 2006.

[12] 박정환, 유비쿼터스 컴퓨팅 환경에서 디지털 포트폴 리오 평가 시스템 설계, 한국산학기술학회논문지, Vol. 9 No.1, pp.214-220, 2008.

\section{박 정 환(Jung-Hwan Park)}

[정회원]

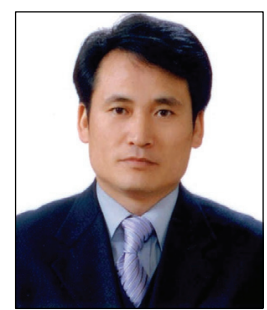

- 1992년 2월 : 원광대학교 교육학 과(문학사)

- 1994년 2월 : 원광대학교 교육학 과(문학석사)

- 2001년 2월 : 한국교원대학교 교 육학과(교육학박사)

- 2004년 9월 현재 : 제주대학 교 교육학과 조교수

<관심분야>

교육공학, 유러닝(U-Learning), 포트폴리오 평가

\section{정 동 욱(Dong-Uk Cheong)}

[정회원]

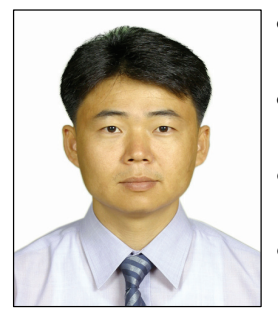

- 1992년 2월 : 한국교원대학교 생 물교육과(교육학사)

- 2007년 2월 : 한국교원대학교 교 육학과(교육학석사)

- 2007년 3월 현재 : 한국교원 대학교 교육학과(박사과정)

- 2009년 9월 현재 : University of Virginia, Visiting Scholar

<관심분야>

교육공학, 교사교육, 가상현실의 교육적 활용

\section{박 형 성(Hyung-Sung Park)}

[정회원]

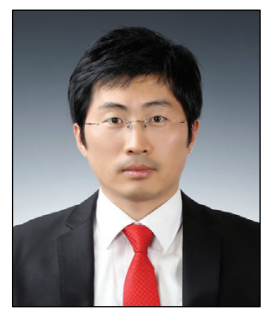

- 2006년 2월 : 한국교원대학교 교 육학과 (교육학석사)

- 2009년 2월 : 한국교원대학교 교 육학과 (교육학박사)

- 2006년 9월 현재 : 충북대학 교 강사

- 2009년 3월 현재 : 경기대학 교 강사

- 2008년 3월 현재 : CyberPsychology and Behavior 심사위원

<관심분야>

게임기반학습, 가상현실교육, 이러닝 